\title{
Self-Assembling Monolayers of Stearic Acid in Protection of Steel
}

\author{
Katarina Marušić, ${ }^{1, *}$ Helena Otmačić Ćurković2
}

\footnotetext{
1 Ruđer Bošković Institute, Bijenička c. 54, HR-10000 Zagreb, Croatia

2 Faculty of Chemical Engineering and Technology, University of Zagreb, Marulićev trg 19, HR-10000 Zagreb, Croatia

* Corresponding author's e-mail address: kmarusic@irb.hr
}

RECEIVED: October 10, 2018 * REVISED: December 18, 2018 * ACCEPTED: December 20, 2018

\begin{abstract}
Carbon steel corrodes severely in presence of sodium chloride and it needs additional protection to be used in marine environments. This work investigates the possibility of using a layer of stearic acid as protection for carbon steel. Stearic acid was applied on the steel by two types of treatments: chemical preparation - by immersion of a steel sample in the SA solution and electrochemical preparation - by imposing a corresponding potential to the system. The results have shown that although both treatments result in obtaining an ordered aliphatic monolayer and both treatments increase the hydrophobicity of the surface, protection that the electrochemical preparation offers is stable in time, while the protection the chemical preparation offers is not.
\end{abstract}

Keywords: corrosion, carbon steel, self-assembled monolayer, electrochemically directed assembly, electrochemical impedance spectroscopy, fourier transform infrared spectroscopy.

\section{INTRODUCTION}

ARBON steels corrode uniformly in a wide variety of environments, yet they are cost-effective compared to stainless steel. The corrosion of carbon steels in marine environments varies widely and is dependent on local conditions. The dissolution of a protected carbon steel construction leads to its decay, as well as environmental pollution. Thus, carbon steel is seldom exposed to its environment without a coating or cathodic protection.

Self-assembled monolayers (SAMs) are ordered molecular assemblies formed by chemisorption of organic molecules onto the substrate surface. Such layers have many advantages, among which: formation on rough, irregular and inner surfaces; the possibility of recovering a damaged SAM in situ if in the immediate vicinity appropriate molecules are present; a monolayer is enough to change the properties of a very large surface; cost-effectiveness since small amounts of material are needed to cover very large areas; and low environmental pollution. ${ }^{[1,2]}$

In corrosion protection by self-assembled monolayers, an appropriate organic molecule should be chosen. The molecule should have protective properties towards corrosion and also specific affinity for the metal surface. The affinity to the solid surface is provided by a covalent chemical reaction, by an ionic interaction, or by a charge transfer complex depending on the molecules and the substrate which they are applied on. ${ }^{[3,4]}$ Fatty acids are an interesting choice. They are carboxylic acids with long aliphatic chains. The use of carboxylic acids to form SAMs has been investigated on stainless steel, ${ }^{[5-7]}$ aluminium oxide ${ }^{[8-10]}$ and copper oxide. ${ }^{10]}$ Their spontaneous adsorption can be considered as an acid-base reaction and the driving force is the formation of a surface salt between carboxylate anion and surface metal cation. ${ }^{[1]}$ Chemicals with long alkyl chains may even possess antimicrobial properties ${ }^{[12]}$ making such layers convenient even for protection from microbial corrosion.

Stearic acid (SA) is a saturated fatty acid with an 18carbon chain. The carboxyl end-group of the molecule has specific affinity for the metal, while the methyl end-group is hydrophobic. Thus, the molecule attaches to the surface in such a way that the methyl group is pointing outwards and so the metal surface becomes hydrophobic. Once the 
surface is hydrophobic it blocks water molecules access to the metals surface and the corrosion slows down.

The application of SAMs in protection of metals from corrosion has been studied widely lately since their application should be very simple. In theory, it is only needed to expose the metal surface to a solution containing molecules with self-assembling properties. In practice, it is more complicated. To achieve best protective properties, the assembling needs to be supported by other treatments, like drying in air or heating, prior to exposure of the metal to the corrosive media. ${ }^{[6,13,14]}$ This process is simple but its reproducibility is relatively low. ${ }^{[15,16]}$

Besides the simple self-assembling method (SAM) of depositing molecules onto the surface from their solution at open circuit potential it is possible to deposit them by electrochemically directed assembly (EDAM). Namely, although the SAM process is simple the obtained layer's reproducibility is relatively low, and in order to obtain highly compact and ordered monolayers several hours are required.[15] This type of assembly is slightly more complicated, since appropriate equipment is needed, but the application is extremely fast and produces monolayers with very low level of structural defects. ${ }^{[15,16]}$ In this case the assembly formation is directed by controlling the voltage. ${ }^{[16-19]}$

This work investigates the possibility of protecting carbon steel by a monolayer of stearic acid applied to the surface by self-assembling as well as by electrochemically directed assembly.

\section{MATERIAL AND METHODS}

\section{Sample Preparation}

Investigations were performed on low-carbon steel (C45E) samples obtained from Strojopromet - Zagreb d. o. o., with a composition given in Table 1. The specimens were cut out from a steel rod with a $1.3 \mathrm{~cm}$ diameter and approximately $0.5 \mathrm{~cm}$ in thickness. A corrosion cell was used for the electrochemical measurements and thus the surface of the samples exposed to the electrolyte was $1 \mathrm{~cm}^{2}$.

In order to prepare working electrodes for long-term exposure to the test solution, on the back-side of these plates a copper wire was soldered, and then they were embedded into epoxy resin. The exposed surface of the working electrodes was again $1 \mathrm{~cm}^{2}$.

The steels were, prior to all investigations and/or surface treatments, abraded with emery paper grade 80 ,
$240,320,400,800,1200,2500$, degreased with ethanol in ultrasonic bath and dried in air.

The protective properties of a monolayer of stearic acid, $\mathrm{CH}_{3}\left(\mathrm{CH}_{2}\right)_{16} \mathrm{CO}_{2} \mathrm{H}(\mathrm{SA})$, were investigated. The SA solutions were prepared by diluting stearic acid (sigma-Aldrich Chemie $\mathrm{GmbH}$ ) in $96 \%$ ethanol.

The monolayer was formed by two types of treatments: (1) chemical preparation - by immersion of a steel sample in the SA solution in ethanol and (2) electrochemical preparation - by imposing a corresponding potential to the steel sample in the same solution.

\section{CHEMICAL PREPARATION (CP)}

A protective film was prepared on the surface of steel according to different procedures that all have three stages: (1) an oxide formation period, (2) a SA treatment period and (3) a drying period. Prior investigations ${ }^{[13]}$ have shown that for the monolayer to form properly these stages are needed. For heating the samples and/or solutions furnace was used. During oxide formation period (1), samples were left in air for $72 \mathrm{~h}$ at room temperature. Then, during the SA treatment period (2) samples were immersed in SA solution at room temperature or at $40^{\circ} \mathrm{C}$. The electrodes were, after being emerged from the inhibitor solution, left to dry in furnace at $50{ }^{\circ} \mathrm{C}$ during the drying period (3).

\section{ELECTROCHEMICAL PREPARATION (EP)}

Electrochemical preparation was performed in a threeelectrode cell, in an ethanol solution containing $0.01 \mathrm{~mol} \cdot \mathrm{dm}^{-3} \mathrm{SA}$ and $0.1 \mathrm{~mol} \cdot \mathrm{dm}^{-3} \mathrm{LiClO}_{4} \cdot \mathrm{H}_{2} \mathrm{O}$. Platinum foil was used as counter electrode and a saturated calomel electrode (SCE) as reference electrode. All potentials in the text refer to the SCE scale. Prior to electrochemical preparation the electrodes were immersed in the test solution for 1 hour in order for SA to adsorb on the surface.

\section{Electrochemical Investigations}

Electrochemical investigations were conducted in a threeelectrode cell, in a solution simulating seawater, $3 \% \mathrm{NaCl}$. Platinum foil was used as counter electrode and SCE as reference electrode. Prior to electrochemical measurements the electrodes were immersed in the test solution for 1 hour to stabilize the open circuit potential.

Electrochemical impedance spectroscopy was performed at $E_{\text {corr }}$ in the frequency range $100 \mathrm{kHz}-10 \mathrm{mHz}$ with a $10 \mathrm{mV} \mathrm{rms}$ amplitude. The wide potential range polarization ( $\pm 150 \mathrm{mV} v$ s. OCP) and narrow ( $\pm 20 \mathrm{mV} v$ s. OCP) were

Table 1. Composition of the investigated steel samples in $\omega / \%$.

\begin{tabular}{ccccccccccc}
\hline & $C$ & Si & Mn & $P$ & S & Cr & Mo & Ni & Other \\
\hline C45E (CS) & 0.42 & $\leq 0.40$ & $0.50-0.80$ & $\leq 0.035$ & $\leq 0.035$ & $\leq 0.4$ & $\leq 0.10$ & $\leq 0.40$ & $\mathrm{Cr}+\mathrm{Mo}+\mathrm{Ni} \leq 0.63$ \\
\hline
\end{tabular}

Croat. Chem. Acta 2018, 91(4), 427-433

DOI: $10.5562 /$ cca3436 
performed at potential scan rate of $0.166 \mathrm{mV} \mathrm{s}^{-1}$. The electrochemical measurements were performed using a PAR $263 \mathrm{~A}$ potentiostat / galvanostat and frequency response detector PAR 1025.

\section{Surface Layer Investigations}

The contact angles of water on different steel samples were measured using a goniometer DataPhysics Contact Angle System OCA 20. Measurements were carried out with a drop of $1 \mu \mathrm{L}$ distilled water under the ambient atmospheric conditions.

FTIR measurements were carried out by PerkinElmer Spectrum One. The scan range was $4000-650 \mathrm{~cm}^{-1}$ having a resolution of $0.5 \mathrm{~cm}^{-1}$. The results were the averages of 4 scans.

\section{RESULTS AND DISCUSSION}

First the CP and EP procedures were optimized and compared. After that the long-time exposure to sodium chloride solution was investigated and the surface analysis were performed.

\section{Chemical Preparation $(C P)$}

The CP investigations were performed by optimizing the SA treatment period. The optimal concentration of the SA solution was investigated, as well as exposure time to the solution.

\section{OPTIMAL CONCENTRATION DETERMINATION}

The influence of SA concentration on monolayer protective properties was examined by polarization measurements in wide potential range $( \pm 0.15 \mathrm{~V})$. Figure 1 presents selected polarization curves obtained on samples that were treated with different concentrations of SA, while Table 2 presents the corrosion parameters obtained from all the measured polarization curves.

It is clear from Figure 1 that all curves presenting SA treated samples shift towards lower current densities in the

Table 2. Corrosion parameters obtained from the polarization curves of samples that were immersed in solutions with different concentrations of SA by Tafel extrapolation method.

\begin{tabular}{cccccc}
\hline $\begin{array}{c}c / \\
\mathrm{mol} \cdot \mathrm{dm}^{-3}\end{array}$ & $\begin{array}{c}E_{\text {corr }} / \\
\mathrm{mV}\end{array}$ & $\begin{array}{c}b_{\mathrm{a}} / \\
\mathrm{mV} \cdot \mathrm{dec}^{-1}\end{array}$ & $\begin{array}{c}-b_{\mathrm{c}} / \\
\mathrm{V} \cdot \mathrm{dec}^{-1}\end{array}$ & $\begin{array}{c}j_{\text {corr }} / \\
\mu \mathrm{A} \cdot \mathrm{cm}^{-2}\end{array}$ & $\begin{array}{c}z / \\
\%\end{array}$ \\
\hline- & $-675 \pm 24$ & $129 \pm 14$ & $0.5 \pm 0.3$ & $79.17 \pm 15.16$ & - \\
$10^{-4}$ & $-581 \pm 20$ & $88 \pm 8$ & $1.5 \pm 1.4$ & $38.98 \pm 4.86$ & 50.8 \\
$10^{-3}$ & $-517 \pm 68$ & $66 \pm 22$ & $6.8 \pm 2.4$ & $26.99 \pm 5.78$ & 65.9 \\
$5 \times 10^{-3}$ & $-631 \pm 11$ & $78 \pm 6$ & $2.5 \pm 1.3$ & $25.43 \pm 3.63$ & 67.9 \\
$10^{-2}$ & $559 \pm 45$ & $55 \pm 26$ & $3.1 \pm 1.3$ & $25.47 \pm 5.17$ & 67.8 \\
$3 \times 10^{-2}$ & $-607 \pm 5$ & $65 \pm 5$ & $6.0 \pm 4.6$ & $26.58 \pm 1.79$ & 66.4 \\
\hline
\end{tabular}

whole investigated potential range and that they all shift towards more positive potentials, i.e. in the more noble direction. It can be seen in Table 2 that the concentrations in the range from $10^{-3} \mathrm{M}$ to $3 \times 10^{-2} \mathrm{M}$ have relatively similar corrosion current densities and thus efficiencies. Concentrations $10^{-2}$ and $5 \times 10^{-3} \mathrm{M}$ have practically the same parameters, but from Figure 1 it can be seen that the cathodic branches are similar for all three concentrations while the anodic branch is shifted towards lower current densities only for the concentration $10^{-2} \mathrm{M}$. Thus, we can conclude that this is the optimal concentration, since at higher concentrations the anodic branch is again back in the higher current densities region.

\section{OPTIMAL EXPOSURE TIME TO SA}

Once the optimal concentration of SA was determined, exposure time to the solution with this concentration was investigated. Figure 2 presents the selected polarization curves obtained on samples that were treated with different exposure time to SA solution, while Table 3 presents the corrosion parameters obtained from all the measured polarization curves.

It is obvious that the optimal exposure time is 7 hours. Both shorter, as well as longer exposure time leads to higher current densities for cathodic and anodic branches. By using the optimal exposure time, the inhibition efficiency of SAM increases from $67.9 \%$ (Table 2) to $80.3 \%$ (Table 3 ).

\section{Electrochemical Preparation (EP)}

To choose the potentials for EP of the monolayer anodic polarization was performed in an ethanol solution

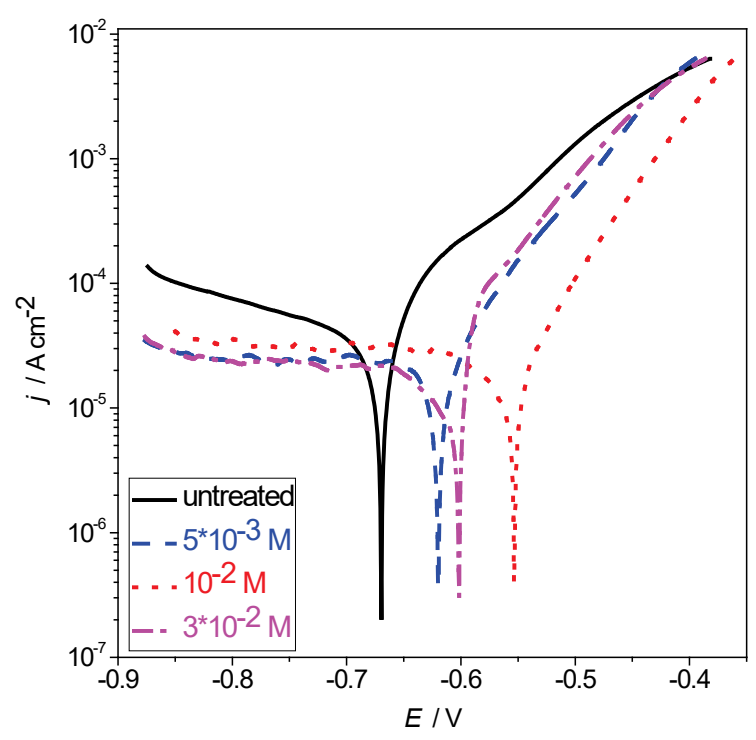

Figure 1. Polarization curves of samples that were treated with different concentrations of SA. 


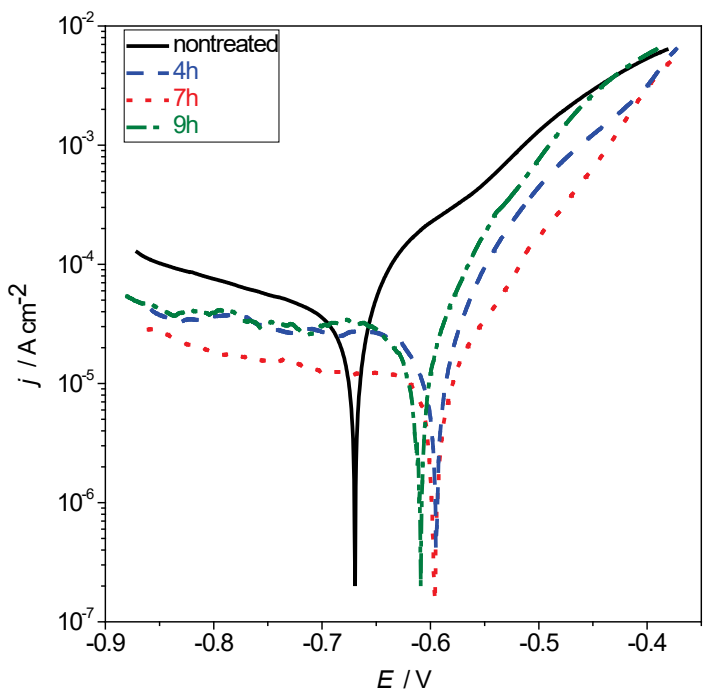

Figure 2. Polarization curves of samples that were treated with different exposure time to SA.

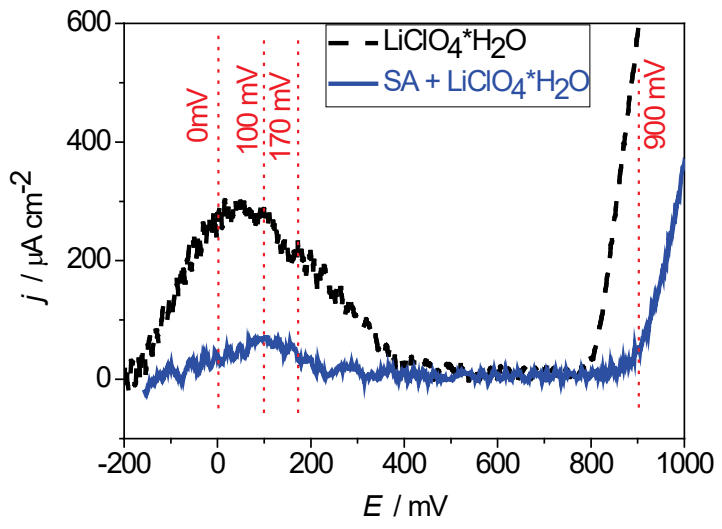

Figure 3. Anodic polarization curves of steel in ethanol solutions.

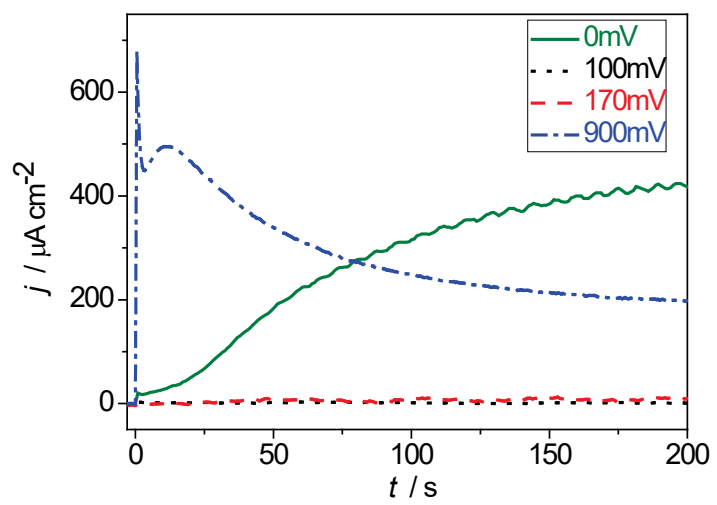

Figure 4. Chronoampermetric curves obtained at different potentials. containing SA and $\mathrm{LiClO}_{4}$ as well as in a solution containing only $\mathrm{LiClO}_{4} \cdot \mathrm{H}_{2} \mathrm{O}$. $\mathrm{LiClO}_{4} \cdot \mathrm{H}_{2} \mathrm{O}$ is added to the solution to increase its conductivity. Figure 4 presents the obtained anodic curves. Four potentials were chosen to investigate: (1) $0 \mathrm{mV}$ - potential where active oxidation of the metal takes place; (2) $100 \mathrm{mV}$ - potential of the highest peak of the activation period, where the metal dissolves continuously; (3) $170 \mathrm{mV}$ - a potential in the region where the passive film forms on the surface of steel; and (4) $900 \mathrm{mV}-\mathrm{a}$ potential at a beginning of a transpassive region.

Figure 4 presents the chronoampermetric curves obtained on the chosen potentials. It can be seen that at $0 \mathrm{mV}$ active oxidation of the metal is present with continuous increase of current density in time. Only at $900 \mathrm{mV}$ a sharp decrease of anodic current density after only 3 seconds of polarization is observed which can be ascribed to protective SA monolayer formation.

After the electrochemical monolayer formation at $900 \mathrm{mV}$, polarization in wide potential range was performed and the results were compared to the results obtained on the sample treated with the optimal chemical procedure and the non-treated steel sample. The results are presented in Figure 5 and Table 4.

Although the curve on Figure 5 presenting the EP sample showed a larger shift in the more positive, i.e. more noble direction, it showed a somewhat smaller inhibiting efficiency $(71.9 \%)$ compared to the CP sample $(80.3 \%)$ as presented in Table 4.

\section{Long Time Exposure To The Sodium Chloride Solution}

After the CP and EP were optimized stability of the protection was investigated. For this reason, EIS was performed after 1 hour in the $\mathrm{NaCl}$ solution and after 3 days in the solution. Figure 6 presents the collected impedance data. Symbols in the figures represent experimental data and lines the calculated data obtained by fitting the experimental data to the selected equivalent electrical circuit that will be explained in further text.

Table 3. Corrosion parameters obtained from the polarization curves of samples that were immersed in solutions with different concentrations of SA by Tafel extrapolation method.

\begin{tabular}{cccccc}
\hline $\begin{array}{c}t / \\
\mathrm{h}\end{array}$ & $\begin{array}{c}E_{\mathrm{corr}} / \\
\mathrm{mV}\end{array}$ & $\begin{array}{c}b_{\mathrm{a}} / \\
\mathrm{mV} \cdot \mathrm{dec}^{-1}\end{array}$ & $\begin{array}{c}-b_{\mathrm{c}} / \\
\mathrm{V} \cdot \mathrm{dec}^{-1}\end{array}$ & $\begin{array}{c}j_{\mathrm{corr}} / \\
\mu \mathrm{A} \cdot \mathrm{cm}^{-2}\end{array}$ & $\begin{array}{c}z / \\
\%\end{array}$ \\
\hline- & $-675 \pm 24$ & $129 \pm 14$ & $0.5 \pm 0.3$ & $79.17 \pm 15.16$ & - \\
2 & $-648 \pm 9$ & $84 \pm 9$ & $0.6 \pm 0.1$ & $38.97 \pm 5.53$ & 50.8 \\
4 & $-599 \pm 45$ & $55 \pm 26$ & $3.1 \pm 1.3$ & $25.47 \pm 5.17$ & 67.8 \\
7 & $-594 \pm 44$ & $64 \pm 38$ & $1.3 \pm 0.6$ & $15.56 \pm 2.06$ & 80.3 \\
9 & $-611 \pm 2$ & $73 \pm 2$ & $1.5 \pm 0.7$ & $24.74 \pm 5.63$ & 68.8 \\
24 & $-604 \pm 6$ & $87 \pm 4$ & $11.0 \pm 9.7$ & $27.37 \pm 1.06$ & 65.4 \\
\hline
\end{tabular}


It can be seen on the Nyquist plot in Figure 6a that although the EIS spectrum of CP sample has a larger semicircle after 1 hour, after 3 days its size has been reduced, while for the EP sample the semicircle stays the same, indicating that the protection the EP monolayer offers is more stable than in the case of the CP monolayer.

It can be seen on the Nyquist plot (Figure 6a), as well as on the Bode plots (Figures $6 b$ and $c$ ), that all the impedance spectra exhibit only one phase angle maximum,

Table 4. Corrosion parameters obtained from the polarization curves of samples prepared by the CP and EP method, evaluated by the Tafel extrapolation method.

\begin{tabular}{cccccc}
\hline \multirow{2}{*}{ Sample } & $\begin{array}{c}E_{\text {corr }} / \\
\mathrm{mV}\end{array}$ & $\begin{array}{c}b_{\mathrm{a}} / \\
\mathrm{mV} \cdot \mathrm{dec}^{-1}\end{array}$ & $\begin{array}{c}-b_{\mathrm{c}} / \\
\mathrm{mV} \cdot \mathrm{dec}^{-1}\end{array}$ & $\begin{array}{c}j_{\text {corr }} / \\
\mu \mathrm{A} \cdot \mathrm{cm}^{-2}\end{array}$ & $\begin{array}{c}z / \\
\%\end{array}$ \\
\hline untreated & $-675 \pm 24$ & $129 \pm 14$ & $0.5 \pm 0.3$ & $79.17 \pm 15.16$ & - \\
CP & $-594 \pm 44$ & $64 \pm 38$ & $1.3 \pm 0.6$ & $15.56 \pm 2.06$ & 80.3 \\
EP & $-517 \pm 8$ & $33 \pm 25$ & $2.9 \pm 2.3$ & $22.21 \pm 8.21$ & 71.9 \\
\hline
\end{tabular}

Table 5. Fitted EIS data obtained for the samples prepared by the chemical and electrochemical preparation method.

\begin{tabular}{cccccc}
\hline & time & $R_{\mathrm{e}} / \Omega \cdot \mathrm{cm}^{2}$ & $C_{\mathrm{dll}} / \mathrm{mF} \cdot \mathrm{cm}^{2}$ & $n_{\mathrm{dll}}$ & $R_{\mathrm{ct}} / \Omega \cdot \mathrm{cm}^{2}$ \\
\hline \multirow{2}{*}{ untreated } & $1 \mathrm{~h}$ & 7 & 2.795 & 0.77 & 1200 \\
& 3 days & 8 & 3.283 & 0.79 & 1111 \\
\multirow{4}{*}{$\mathrm{CP}$} & $1 \mathrm{~h}$ & 7 & 3.524 & 0.72 & 1803 \\
& 3 days & 7 & 3.529 & 0.75 & 1287 \\
\multirow{2}{*}{ EP } & $1 \mathrm{~h}$ & 6 & 2.385 & 0.74 & 1447 \\
& 3 days & 9 & 2.838 & 0.77 & 1417 \\
\hline
\end{tabular}

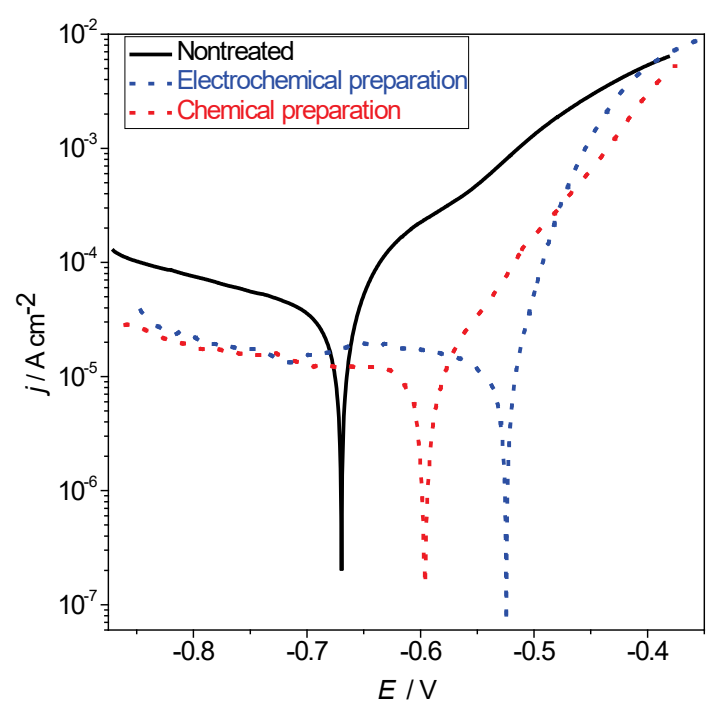

Figure 5. Polarization curves of samples prepared by chemical and electrochemical preparation. i.e. it has only one time constant. Thus, the impedance data have been fitted to a simple equivalent circuit presented in Figure 7. This equivalent circuit consist of electrolyte resistance $\left(R_{\mathrm{e}}\right)$ between a reference and working electrode, $R_{\mathrm{ct}}$ representing charge transfer resistance, $C_{\mathrm{dl}}$ double layer capacitance and $n_{\mathrm{dl}}$, coefficient describing a depressed feature of impedance spectra in Nyquist plot. The fitting results are presented in Table 5.

Similar as from the plots, from obtained impedance parameters it can be seen that for the non-treated sample the double layer resistance is rather small from the beginning $\left(1200 \Omega \mathrm{cm}^{2}\right)$ and with time it decreases furthermore. In comparison, the $\mathrm{CP}$ sample has rather high resistance after 1 hour coupled with relatively high capacitance. With
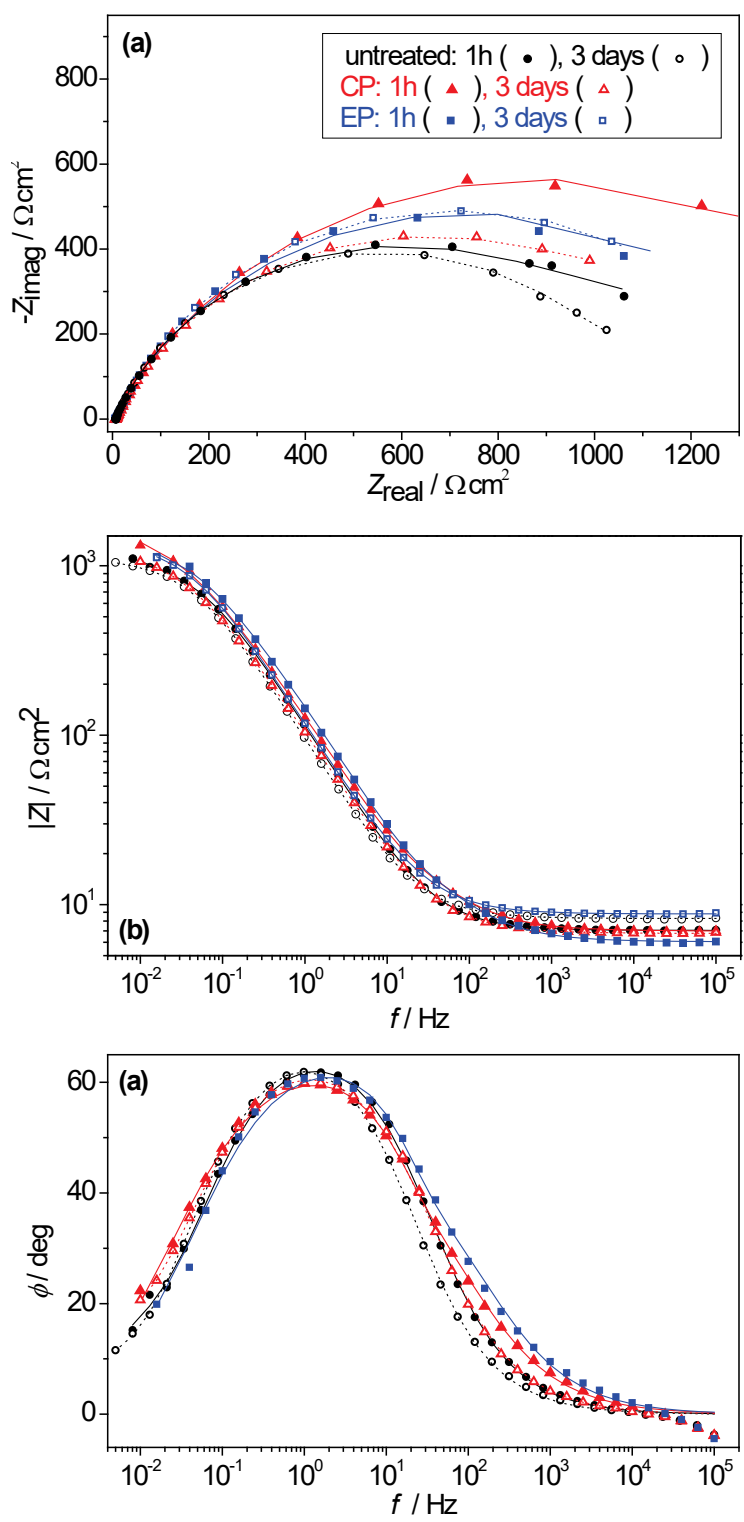

Figure 6. ElS spectra presented in Nyquist and Bode plots of $\mathrm{CS}$ samples exposed to $\mathrm{NaCl}$ solution. 
time the capacitance does not change but the resistance decreases and reaches a value $\left(1287 \Omega \cdot \mathrm{cm}^{2}\right)$ that is similar to the value of the non-treated sample.

For the EP sample the charge transfer resistance after one hour is not as high as for the CP sample, but it is still higher than for the non-treated sample $\left(1447 \Omega \cdot \mathrm{cm}^{2}\right)$ and very stable in time. Also, the capacitance increases, but very slowly, from 2.385 to $2.838 \mathrm{mF} \cdot \mathrm{cm}^{2}$.

It can be concluded that although both treatments offer short-term corrosion protection, only EP offers stable protection to CS. Taking into account the simplicity of the procedure EP has proved to be a better choice.

\section{Contact Angle Measurements}

The hydrophobicity of the surface was investigated by contact angle measurements with a drop of water. Figure 8 presents the results. It can be seen that in presence of SA the contact angle increases largely. It can also be seen that

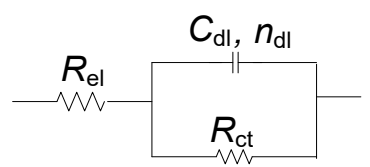

Figure 7. Equivalent electrical circuit used for fitting the EIS data.

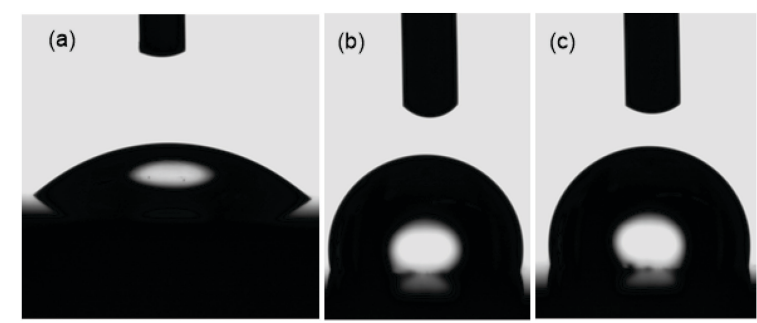

Figure 8. Water contact angle measurements on the (a) nontreated, (b) chemically and (c) electrochemically treated CS samples.

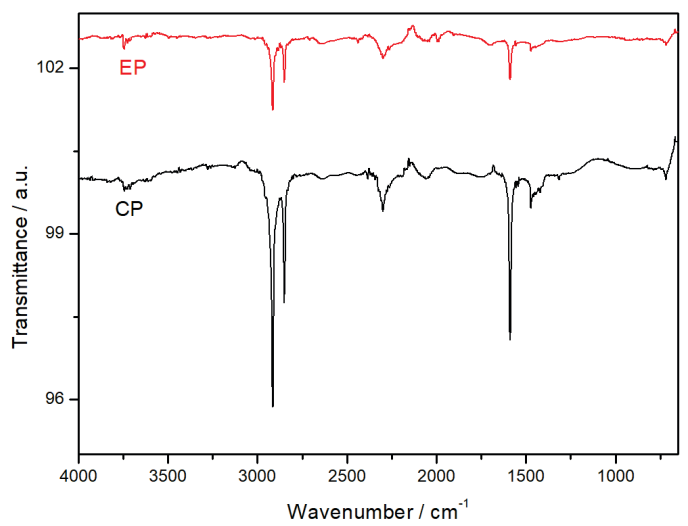

Figure 9. FTIR spectra of chemically and electrochemically treated samples. no matter the treatment procedure the contact angle is always around $105^{\circ}$. Well-ordered and densely packed SAM of SA on various substrates ${ }^{[6,20]}$ have shown a water contact angle of around $108^{\circ}$. The water contact angles, determined on our samples, showed such values indicating that the alkyl tail group is oriented towards environment.

\section{FTIR MEASUREMENTS}

The $\mathrm{C}-\mathrm{H}$ stretching region of the infrared spectrum, obtained using a FTIR spectrometer on both EP and CP SA monolayers is shown in Figure 9. It can be seen that on both (EP, CP) samples similar spectra were obtained. The FTIR spectrum of an "ordered" aliphatic monolayer is one with chains on all-trans configuration and it is characterized by $\left(v_{\mathrm{CH} 2}\right)_{\text {asym }} \sim 2917 \mathrm{~cm}^{-1}$ and $\left(v_{\mathrm{CH} 2}\right)_{\text {sym }} \sim 2849 \mathrm{~cm}^{-1} \cdot{ }^{[1,2]}$ The asymmetric COO- stretching mode is represented by the peak at $\left(v_{\text {coo }}\right)_{\text {asym }} \sim 1589 \mathrm{~cm}^{-1}$, while the symmetric stretching mode is represented with a peak at $\left(v_{\mathrm{COO}}\right)_{\text {sym }} \sim 1473 \mathrm{~cm}^{-1}$.

\section{CONCLUSIONS}

Two types of application procedures for self-assembling monolayers of stearic acid (SA) on low-carbon steel have been investigated: a chemical (CP) and an electrochemical (EP) preparation procedure.

The electrochemical measurements have shown that the protection EP offers to steel is more stable with time compared to the protection $\mathrm{CP}$ offers.

Both treatments increase significantly and to the same extent the contact angle, what indicates that both treatments increase the hydrophobicity of the surface.

FTIR measurements have confirmed the presence of an ordered aliphatic monolayer on the surface of steel prepared both chemically (CP) as well as electrochemically (EP).

It can be concluded that although both treatments offer short-term protection, only EP offers stable protection to CS. Taking into account the simplicity of the procedure EP has proved to be a better choice.

Acknowledgment. The authors are grateful to the "Croatian Science Foundation "for the financial support of the project 9.01/253 „Ecological protection of metal constructions exposed to marine environment".

\section{REFERENCES}

[1] A. R. Bishop, R. G. Nuzzo, Curr. Opin. Coll. In. Sci. 1996, 1, 127.

[2] L. Srisombat, A. C. Jamison, T. R. Lee, Colloids Surf. A Physicochem. Eng. Asp. 2011, 390, 1.

[3] E. Delamarche, B. Michel, Thin Solid Films 1996, 273, 54. 
[4] L. H. Dubois, R. G. Nuzzo, Annu. Rev. Phys. Chem. 1992, 43, 437.

[5] G. Shustak, A. J. Domb, D. Mandler, Langmuir 2004, 20, 7499.

[6] A. Raman, E.S. Gawalt, Langmuir 2007, 23, 2284.

[7] X. Liu, S. Chen, H. Ma, G. Liu, L. Shen, Appl. Surf. Sci. 2004, 253, 814.

[8] K. M. Pertays, G. E. Thompson, M. R. Alexander, Surf. Interface Anal. 2004, 36, 1361.

[9] D. L. Allara, R. G. Nuzzo, Langmuir 1985, 1, 45.

[10] Y. T. Tao, J. Am. Chem. Soc. 1993, 115, 4350.

[11] A. Ulman, Chem. Rev. 1996, 96, 1533.

[12] E. Skrivanova, M. Marounek, V. Benda, P. Brezina, Vet. Med. Czech 2006, 51, 81.

[13] K. Marušić, Z. Hajdari, H. Otmačić Ćurković, Acta
Chim. Slov. 2014, 61, 328.

[14] K. M. Kruszewski, E. R. Renk, E. S. Gawalt, Thin Solid Films 2012, 520, 4326.

[15] Ž. Petrović, M. Metikoš-Huković, R. Babić, J. of Electroanal. Chem. 2008, 623/1, 54.

[16] W. Paik, S. Eu, K. Lee, S. Chon, M. Kim, Langmuir 2000, 16, 10198.

[17] C. Frubose, K. Doblhofer, J. Chem. Soc. Faraday Trans. 1995, 91, 1949.

[18] H. Ron, I. Rubinstein, J. Am. Chem. Soc. 1998, 120, 13444.

[19] M. Dijksma, B. Kamp, J. C. Hoogvliet, W. P. van Bennekom, Langmuir 2000, 16, 3852.

[20] A. Raman, R. Quinones, L. Barriger, R. Eastman, A. Parsi, and E. S. Gawalt, Langmuir 2010, 26, 1747. 